\title{
RedEfish: Generation of the Polycistronic mScarlet: GSG-T2A: Ttpa Zebrafish Line
}

\author{
Brian Head ${ }^{1,2,+}{ }^{D}$, Jane La Du ${ }^{3}$, Carrie Barton ${ }^{3}$, Jie Zhang ${ }^{1,4}$, Carmen Wong ${ }^{1}$, Emily Ho ${ }^{1,5}$, Robyn L. Tanguay ${ }^{3} \mathbb{D}$ \\ and Maret G. Traber $1,5, * \mathbb{D}$
}

1 Linus Pauling Institute, Oregon State University, Corvallis, OR 97331, USA; Brian.Head@oregonstate.edu or brian.head@nih.gov (B.H.); catherin@cau.edu.cn (J.Z.); carmen.wong@oregonstate.edu (C.W.); emily.ho@oregonstate.edu (E.H.)

2 Molecular and Cell Biology Program, Oregon State University, Corvallis, OR 97331, USA

3 Department of Environmental Toxicology, College of Agricultural Sciences, Oregon State University, Corvallis, OR 97331, USA; Jane.LaDu@oregonstate.edu (J.L.D.); Carrie.Barton@oregonstate.edu (C.B.); robyn.tanguay@oregonstate.edu (R.L.T.)

4 College of Science, China Agriculture University, Beijing 100083, China

5 School of Biological and Population Health Sciences, College of Public Health, Oregon State University, Corvallis, OR 97331, USA

* Correspondence: maret.traber@oregonstate.edu

+ Current address: National Institutes of Health, National Institute of Child Health and Human Development, Bethesda, MD 20817, USA.

check for updates

Citation: Head, B.; La Du, J.; Barton, C.; Zhang, J.; Wong, C.; Ho, E.; Tanguay, R.L.; Traber, M.G. RedEfish: Generation of the Polycistronic mScarlet: GSG-T2A: Ttpa Zebrafish Line. Antioxidants 2021, 10, 965. https://doi.org/10.3390/ antiox10060965

Academic Editors: Kavindra Kumar Kesari, Dhruv Kumar, Niraj Kumar Jha and Janne Ruokolainen

Received: 18 May 2021

Accepted: 10 June 2021

Published: 16 June 2021

Publisher's Note: MDPI stays neutral with regard to jurisdictional claims in published maps and institutional affiliations.

Copyright: (c) 2021 by the authors. Licensee MDPI, Basel, Switzerland. This article is an open access article distributed under the terms and conditions of the Creative Commons Attribution (CC BY) license (https:// creativecommons.org/licenses/by/ $4.0 /)$.
Abstract: The vitamin E regulatory protein, the alpha-tocopherol transfer protein (Ttpa), is necessary for zebrafish embryo development. To evaluate zebrafish embryo Ttpa function, we generated a fluorescent-tagged zebrafish transgenic line using CRISPR-Cas9 technology. One-cell stage embryos (from Casper (colorless) zebrafish adults) were injected the mScarlet coding sequence in combination with cas 9 protein complexed to single guide RNA molecule targeting $5^{\prime}$ of the ttpa genomic region. Embryos were genotyped for proper insertion of the mScarlet coding sequence, raised to adulthood and successively in-crossed to produce the homozygote RedEfish (mScarlet: GSG-T2A: Ttpa). RedEfish were characterized by in vivo fluorescence detection at 1, 7 and 14 days post-fertilization (dpf). Fluorescent color was detectable in RedEfish embryos at $1 \mathrm{dpf}$; it was distributed throughout the developing brain, posterior tailbud and yolk sac. At $7 \mathrm{dpf}$, the RedEfish was identifiable by fluorescence in olfactory pits, gill arches, pectoral fins, posterior tail region and residual yolk sac. Subsequently (14 dpf), the mScarlet protein was found in olfactory pits, distributed throughout the digestive tract, along the lateral line and especially in caudal vertebrae. No adverse morphological outcomes or developmental delays were observed. The RedEfish will be a powerful model to study Ttpa function during embryo development.

Keywords: vitamin E; alpha-tocopherol; alpha-tocopherol transfer protein (TTPA)

\section{Introduction}

Vitamin E (VitE, $\alpha$-tocopherol) is necessary for embryonic development [1]. Low maternal VitE in human serum and cord blood is linked to prematurity, low birth weight [2], increased risk of miscarriage [3] and intrauterine growth restriction [4]. Preterm babies were found with lower VitE relative to term babies of mothers with similar cord blood VitE levels [5] and circulating VitE in women at early and late term was positively correlated to fetal growth and decreased risk for low birth weight [6].

VitE deficiency in humans can be caused by genetic defects in the $\alpha$-tocopherol transfer protein (TTPA (Ttpa in zebrafish), note that human, mouse and rat proteins are indicated by all capital letters, while zebrafish proteins are indicated by a capitalized first letter) $[7,8]$. TTPA is localized primarily in hepatocytes, where it facilitates VitE trafficking from recycling endosomes to the membrane in exchange for inositol-triphosphate (Ins3P) [9], the 
transfer of VitE to nascent lipoproteins is then facilitated by ABCA1 [10], an ATP-dependent transporter. In addition to the liver, TTPA is also expressed in the human yolk sac [11] and in placental uterine lining at the site of implantation [12]. Limited information exists, however, about the role of Ttpa in the developing embryo.

Zebrafish embryos are a frequently used model for developmental biology because they develop externally are transparent, easy to maintain and are produced in large quantities [13]. The zebrafish embryo has been used as a powerful tool to study numerous human-health related conditions, including birth defects [14-19]. Importantly, early development gene expression networks are highly conserved between zebrafish and humans [20], especially the sequence for ttpa (64.3\% protein sequence homology between zebrafish and human). Zebrafish require both vitamins $\mathrm{E}$ and $\mathrm{C}$, so are highly relevant for antioxidant research [21,22]. Thus, the VitE-deficient zebrafish embryo model (E- embryos) allows us to evaluate developmental dysregulation in a highly relevant model. Our research using Eembryos has demonstrated that VitE prevents lipid peroxidative damage [23] and the ensuing metabolic responses aimed to repair the damage [24]. We found that these metabolic responses are detrimental because they deplete critical nutrients and waste limited energy resources needed for embryo development [24-26]. Indeed, supplementation of the Eembryos with VitE, or glucose, rescued the animals [24,25]. These metabolic abnormalities were associated with dysregulation of gene networks under the control of mechanistic target of rapamycin (mTORC1) [27]. Further, E- embryos show significant morphologic abnormalities as early as $12 \mathrm{hpf}$ [28]. VitE was necessary for brain (fore, mid and hindbrain) development at $12 \mathrm{hpf}$ and later ( $24 \mathrm{hpf}$ ) for the dorsal root ganglia and notochord formations [28]. The ttpa gene is expressed in the zebrafish brain ventricle borders, eye and tailbud at $24 \mathrm{~h}$ post-fertilization (hpf) [28,29]. Translation- and splice-blocking morpholinos preventing Ttpa synthesis caused 100\% lethality in zebrafish embryos by $24 \mathrm{hpf}$ [29]. These findings suggest that TTPA and VitE have important functions in the embryo separate from placental implantation. During embryogenesis, TTPA could potentially function to (1) transfer VitE from the yolk to the developing embryo, (2) facilitate VitE transport from the placenta to the embryo and (3) regulate VitE trafficking in cells of the developing nervous system in the embryo.

We hypothesize that studies of Ttpa localization in the embryo will provide critical information concerning its essential function to deliver VitE to target sites. To test this hypothesis, we developed a transgenic zebrafish model containing a red fluorophore tagged Ttpa. CRISPR-cas9 technology was used to knock-in a genomic mScarlet sequence $5^{\prime}$ upstream of the ttpa genomic sequence separated by a self-cleaving viral peptide sequence (GSG-T2A). We used mScarlet because it is a powerful red fluorophore with more intensity (0.54 quantum yield units) and longer lifetime (3.1 ns) than other known red fluorescent proteins [30]. The $\mathrm{mScarlet}$ protein is not cytotoxic and has been shown previously to be effective for creation of transgenic zebrafish lines [31]. We report herein the creation of the RedEfish (mScarlet: GSG-T2A: Ttpa) transgenic line.

\section{Materials and Methods}

\subsection{Zebrafish Husbandry and Strains}

All experimental protocols and methods were carried out in accordance with the animal use and care protocol (\# 5068) approved by the Institutional Animal Care and Use Committee at Oregon State University. 5D tropical strain and Tg zebrafish (Casper; mitfa ${ }^{\text {w2/w2 }}$,

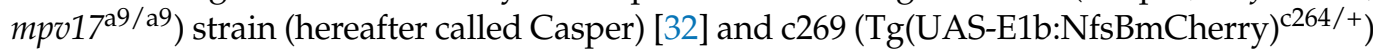
strain (hereafter called c269) [33] were reared in Sinnhuber Aquatic Research Laboratory at Oregon State University under standard laboratory conditions of $28^{\circ} \mathrm{C}$ on a $14 \mathrm{~h}$ light $/ 10 \mathrm{~h}$ dark photoperiod according to standard zebrafish breeding protocols [34]. The 5D tropical strain and the c269Tg reporter line zebrafish were used as additional negative and positive controls for experiments, noted throughout. 


\subsection{Construction of Donor Plasmid and Guide RNA Vectors for Knock-In}

The donor plasmid containing homology arms to the ttpa genomic sequence (GenBank:BX248497, RefSeq:NM_199731), mScarlet sequence, Gly-Ser-Gly linker (GSG) sequence and 2A self-cleaving peptide (T2A) was constructed and supplied by In Vivo Biosystems, Inc. (Eugene, OR, USA). Constructs were assembled by Gibson ligation and confirmed by digest at restriction sites Pvul and Pvull, followed by sequencing. A single guide RNA (sgRNA) sequence was designed with the custom designed short CRISPR RNA (crRNA) sequence fused to the scaffold trans-activating CRISPR RNA (tracRNA) sequence (Figure 1).

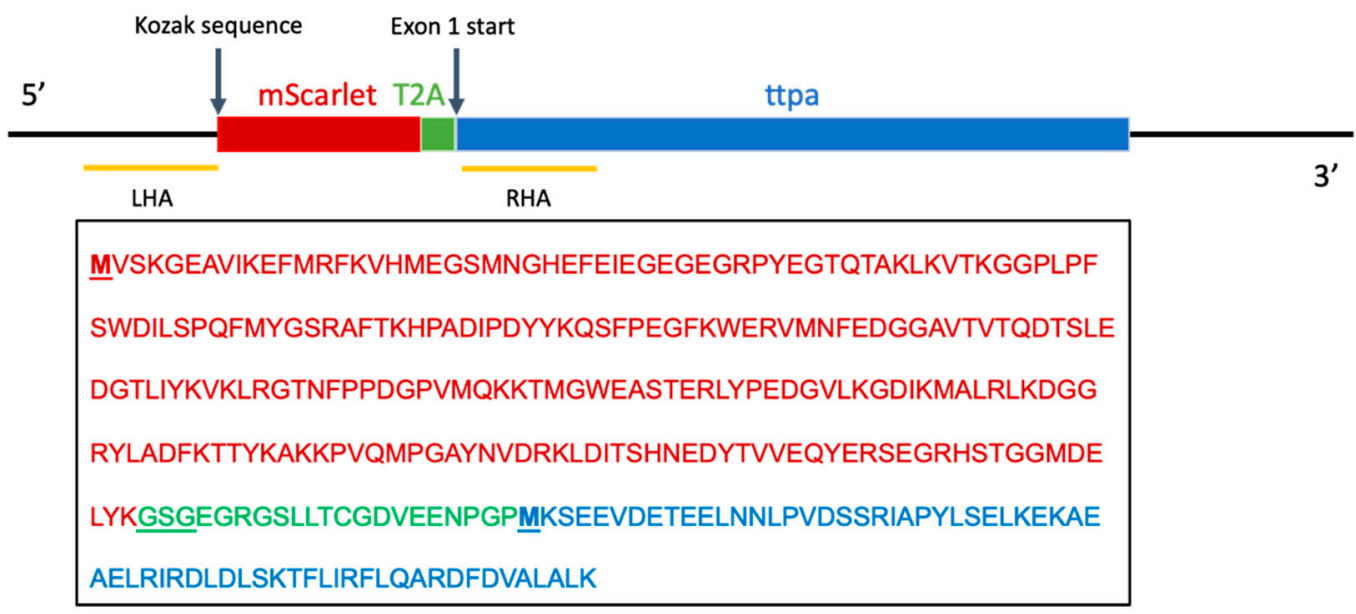

Figure 1. Knock-in strategy and designed protein sequence. LHA refers to the left homology arm and RHA refers to the right homology arm of the donor plasmid containing the mScarlet coding sequence. Amino acid sequences are denoted by color to indicate protein: mScarlet (red), GSG-T2A linker site (green) and exon 1 of ttpa (blue).

\subsection{Microinjection}

sgRNA and cas9 protein were complexed and coinjected into one-cell stage zebrafish embryos. Approximately $1 \mathrm{~nL}$ of injection mix $(10.5 \mu \mathrm{M}$ sgRNA, $500 \mathrm{ng} / \mu \mathrm{L}$ cas9, $50 \mathrm{ng} / \mu \mathrm{L}$ donor plasmid and $50 \mu \mathrm{M}$ NU7441 in 1\% DMSO) was injected directly into each embryo. Embryos were then placed on ice-cold 1.5\% agarose for no more than $15 \mathrm{~min}$. NU7441 and cold exposure after injection were used to improve knock-in efficiency of mScarlet sequence by homology-directed repair mechanisms (HDR) [35]. NU7441 in 1\% DMSO $(50 \mu \mathrm{M})$ injected at the levels described did not have deleterious effects on normal zebrafish embryos, as assessed by morbidity, mortality and behavioral outcomes at 5 days postfertilization (dpf) [36]. Injected embryos were collected, staged, and incubated in standard embryo media ((EM), $15 \mathrm{mM} \mathrm{NaCl}, 0.5 \mathrm{mM} \mathrm{KCl}, 1 \mathrm{mM} \mathrm{MgSO}_{4}, 0.15 \mathrm{mM} \mathrm{KH}_{2} \mathrm{PO}_{4}, 0.05 \mathrm{mM}$ $\mathrm{Na}_{2} \mathrm{HPO}_{4}, 1 \mathrm{mM} \mathrm{CaCl}$ and $\mathrm{NaHCO}_{3}$ in fish system water).

\subsection{Mutation Detection and Insertion Mapping}

Genomic DNA (gDNA) was extracted from injected embryos $(n=32)$ at $5 \mathrm{dpf}$ after each trial, as described [37]. Embryos were euthanized with tricaine (MS222, ethyl 3aminobenzoate methanesulfonate salt (Sigma Aldrich, St. Louis, MO, USA)) in accordance with animal care and use guidelines, placed in $50 \mu \mathrm{L} 50 \mathrm{mM} \mathrm{NaOH}$ and incubated at $95^{\circ} \mathrm{C}$ for $15 \mathrm{~min}$. DNA extraction was stopped with $10 \mu \mathrm{L} 1 \mathrm{M}$ TRIS $\mathrm{pH} 8.0$, and stored in $4^{\circ} \mathrm{C}$ until use.

PCR reactions were performed with primers designed to capture the complete insertion region (Table 1). Target regions were amplified by PCR and sequenced by Sanger Sequencing at the Center for Genome Research and Biocomputing (CGRB) at Oregon State University. Adult zebrafish were fin clipped at 3 months, gDNA extracted and PCR performed as described above. Identified insertion carriers were out-crossed with 
Casper zebrafish to produce $\mathrm{F} 1$ heterozygotes $\mathrm{Tg}\left(\mathrm{mScarlet}: \mathrm{ttpa} ; \mathrm{mScarlet}^{+/-}\right.$, mitfa $^{\mathrm{w} 2 / \mathrm{w} 2}$, mpv17 ${ }^{\mathrm{a} 9 / \mathrm{a} 9}$ ), which were then successively in-crossed to produce F2 heterozygotes and F3 homozygotes (hereafter called RedEfish).

Table 1. Primers designed for insertion mapping.

\begin{tabular}{ccc}
\hline Primer Purpose & Sequence $\left(\mathbf{5}^{\prime} \mathbf{- 3}^{\prime} \mathbf{)}\right.$ & Product Size (bp) \\
\hline Left homology arm F & AGGCGTGTGTCTCTGTAAGG & 418 \\
Left homology arm R & GCCGTACATGAACTGAGGGG & \\
Right homology arm F & CGCTACCTGGCGGACTTC & 309 \\
Right homology arm R & AATCCGGGAGGAATCAACAGG & 121 no insertion \\
mScarlet cassette F & CGCTCTGAGAACAACATGACAC & 879 insertion \\
mScarlet cassette R & GACAAATATGGTGCAATCCGGG &
\end{tabular}

Primers designed for left and right homology arms were first utilized to identify germ-line transmission of the $\mathrm{mScarlet}$ sequence. Successful insertion and validation of $\mathrm{mScarlet}$ expression determined with $\mathrm{mScarlet}$ cassette primers. All primers designed with NCBI primer Blast. $\mathrm{F}=$ forward primer, $\mathrm{R}=$ reverse primer.

\subsection{In Vivo Fluorescence Detection}

Live embryo imaging was conducted using a Keyence BZ-x700 All-in-one microscope with a $2 \times$ or $10 \times$ objective and $644 \mathrm{~nm}$ filter. Live embryos were mounted in $3 \%$ methylcellulose at room temperature in $35 \mathrm{~mm}$ glass bottom MatTek dishes and covered in embryo media and tricaine to anesthetize live embryos. Image adjustments, including cropping, brightness and contrast were performed uniformly using Adobe Photoshop.

\subsection{Egg Quality and Embryo Morphological Assessment}

RedEfish embryos were collected, staged, and incubated in standard EM. Egg traits were assessed by egg yolk diameter followed by egg volume estimated based on the volume of an ellipsoid using the equation [38,39]:

$$
\text { Volume }=(4 / 3) \pi \times(\text { small axis radius }) \times(\text { large axis radius })^{2}
$$

At $24 \mathrm{hpf}$ and $5 \mathrm{dpf}$, RedEfish and Casper embryos were assessed for morbidity and mortality outcomes, as described [36,40]. RedEfish and Casper 5 dpf larval $\alpha$ - and $\gamma$-tocopherol concentrations were determined using high-performance liquid chromatography with electrochemical detection, as described with comparison to authentic standards [41].

\subsection{Immunolocalization and Western Blot Analysis}

Distribution of mScarlet protein was assessed in embryos ( $3 \mathrm{dpf})$ using the polyclonal antibody to red fluorescent protein (anti-RFP) (anti-rabbit RFP, 1:3000; abcam, ab62341 (Cambridge, MA, USA)). Monoclonal antibodies generated against acetylated tubulin (mouse anti-goat, 1:4000; Sigma Aldrich (St. Louis, MO, USA)) were used to label axons in the developing embryo as a positive control. Embryos ( $n=15$ per group) at the described time points were fixed overnight in $4 \%$ paraformaldehyde (PFA) in phosphate-buffered saline (PBS), washed in PBS the following morning and stored at $4{ }^{\circ} \mathrm{C}$ in PBS and $0.1 \%$ sodium azide until use. Fixed embryos were washed in PBS + 0.1\% Tween20 (PBST), permeabilized with $0.005 \%$ trypsin in PBS on ice for $5 \mathrm{~min}$, rinsed with PBST and post-fixed in $4 \%$ PFA. Permeabilized embryos were blocked in 10\% normal goat serum in PBS $+0.5 \%$ Triton X-100 for an hour followed by incubation with the primary antibody overnight at $4{ }^{\circ} \mathrm{C}$ in $1 \%$ normal goat serum in PBS and $0.5 \%$ Triton X-100. Embryos were washed 4 times for 30 min in PBST, incubated with secondary antibody (Alexa-488 goat anti-mouse, 1:1000; ThermoFisher (Carlsbad, CA, USA)) for $2 \mathrm{~h}$ and washed 4 times for $30 \mathrm{~min}$ in PBST.

Distribution of Ttpa protein was assessed in zebrafish embryos (5 dpf) using the polyclonal anti-TTPA antibody (rabbit anti-zebrafish Ttpa (L6308, Antibodies Inc., Davis, CA, USA), 1:300). Embryos previously fixed in 4\% PFA were washed in PBST and stored in $100 \%$ methanol. Samples were rehydrated and treated with $10 \mathrm{mg} / \mathrm{mL}$ proteinase 
$\mathrm{K}$ in PBST. Samples were then blocked in 5\% normal goat serum and $3 \mathrm{mg} / \mathrm{mL}$ bovine serum albumin in PBST followed by incubation with the primary antibody. Embryos were washed, incubated with secondary antibody (Alexa-594 goat anti-rabbit, 1:1000; ThermoFisher (Carlsbad, CA, USA)), washed and visualized, as described [42].

All fixed embryo imaging was conducted using Keyence BZ-x700 All-in-one microscope with a $2 \times, 10 \times$ or $20 \times$ objective and $470 \mathrm{~nm}$ or $694 \mathrm{~nm}$ filter, as described above. Image adjustments, including cropping, brightness and contrast were performed uniformly using Adobe Photoshop.

For Western blots, protein was extracted from pooled $(n=25)$ embryos $(24 \mathrm{hpf})$ in RIPA buffer supplemented with protease and protein phosphatase inhibitors (Calbiochem, La Jolla, CA, USA). Rat liver extract and extracts of c269 embryos were used as positive controls for Ttpa and RFP. Extracted protein $(20 \mu \mathrm{g})$ was subjected to SDS-Page and processed by immunoblotting. Antibodies used for Western blotting were anti-ATP synthase F1 subunit $\alpha$ (1:1000, ab110273), anti-Ttpa (1:250, L6308), anti-RFP (1:1000, ab62341), goat anti-rabbit IgG-HRP and goat anti-mouse IgG-HRP secondary antibodies (1:10,000). Nonspecific protein binding was blocked using Tris-buffered saline with $0.1 \%$ Tween 20 (TBST) containing 5\% nonfat dry milk. All antibodies were diluted in TBST containing $1 \%$ bovine serum albumin. Proteins were visualized by SuperSignal ${ }^{\mathrm{TM}}$ West Femto Chemiluminescent Substrate (ThermoFisher, Carlsbad, CA, USA) and quantified using the Bio-Rad Image System (Hercules, CA, USA).

\subsection{Statistical Methods}

Statistical differences between groups were assessed using Student's $t$-test (Prism 6.0, GraphPad, La Jolla, CA, USA). Statistical significance between differences was set at $p<0.05$. Differences between reproductive output and egg yolk volume in $3 \mathrm{hpf}$ embryos was assessed with $t$-tests between Casper and RedEfish. Similarly, the vitamin E contents of the embryos are reported as comparisons between the two fish lines. Additionally, tocopherol data were logarithmically transformed data for each fish line, then 2-factor ANOVA was followed by Holm-Sidak's multiple comparisons test to allow for comparison between $\alpha$ - and $\gamma$-tocopherol concentrations in each fish line. Data are reported as means \pm standard deviation.

\section{Results}

Mosaicism in the founder generation was not immediately apparent by fluorescent imaging. PCR genotyping was utilized to identify sequence expressing fish. About $7.5 \%$ ( $n=19$ of 254) of 3 months old (mo) adults screened were identified as transgenic; one screened adult (male) retained the mScarlet:T2A construct. Success was defined as integration of the mScarlet sequence $5^{\prime}$ of $t$ tpa without erroneous insertions or deletions (INDELs), as determined by Sanger Sequencing. The mosaic founder male was outcrossed with female Casper zebrafish (mitfa ${ }^{\mathrm{w} 2 / \mathrm{w} 2}, m p v 17^{\mathrm{a} 9 / \mathrm{a} 9}$ ) to produce F1 embryos. F1 embryos were raised to 3 months for further in-crossing with the F0 mosaic founder. This in-cross produced F2 heterozygotes, as identified by PCR and sequencing. In vivo fluorescence of heterozygotes was apparent by $5 \mathrm{dpf}$, however, the yolk sac remnants were a significant source of autofluorescence. F3 in-crosses were performed to generate homozygotes. Sequencing of heterozygote embryos indicated two gene products, one containing the mScarlet:ttpa construct and the other containing the unmodified ttpa exon 1 (Supplementary Figure S1). Sequencing about the targeted region show no INDELs either in the $5^{\prime}$ region of mScarlet or in the $5^{\prime}$ region of ttpa exon1 (Supplementary Figure S1).

Fluorescent color was detectable in RedEfish embryos at $1 \mathrm{dpf}$; it was distributed throughout the developing brain, posterior tailbud and largely in the yolk sac (data not shown). In vivo fluorescence was more readily detected during the early larval stage (7 dpf). RedEfish express mScarlet in the olfactory pits (Figure 2A), throughout the liver and digestive tract (Figure 2B,C), and express punctate signals throughout the tail fin and fin edges. By $14 \mathrm{dpf}$, RedEfish express mScarlet throughout the digestive tract. Most 
striking, mScarlet expression was found in the caudal vein plexus, caudal vertebrae, and tail fin. The red fluorescence in the vertebrae is localized to dorsal root ganglia (Figure 2E).
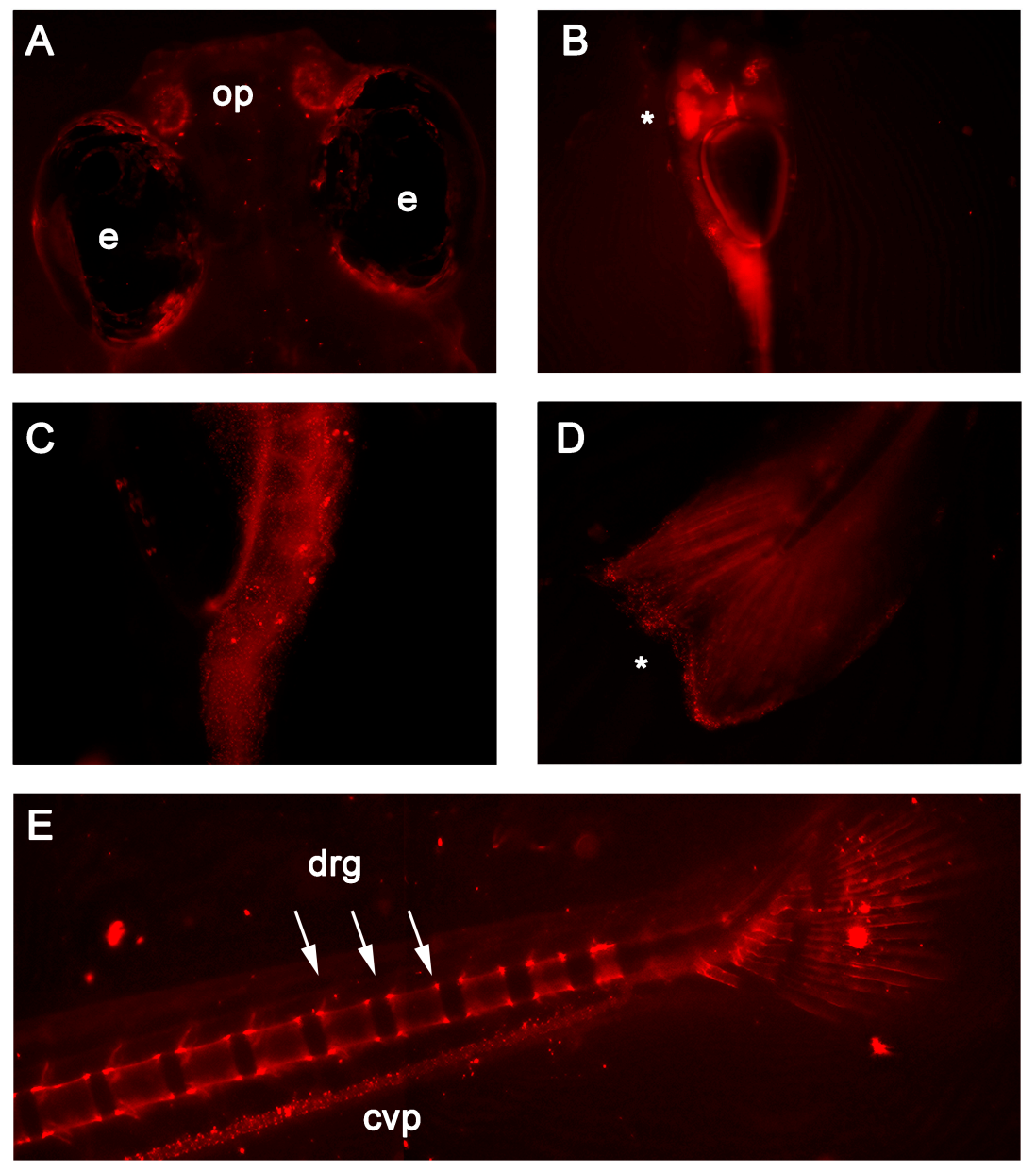

Figure 2. In vivo fluorescence detected in 7 and 14 days post-fertilization RedEfish. (A) mScarlet expression was unique to the olfactory pits (op) found in the RedEfish; however, some autofluorescence was detected in the pigment cells surrounding the eyes (e) in all embryos. (B) mScarlet expression was identified in the digestive tract, specifically the liver (as indicated by *). (C) More punctate expression was observed in the anterior gut region (ventral embryo positioning). (D) Punctate expression was observed also in the tail fin (as indicated by *). (E) By $14 \mathrm{dpf}$, mScarlet expression was identified in the caudal vertebrae and dorsal root ganglia ( $\mathrm{drg}$ ) and was detected in the caudal vein plexus (cpv). Some autofluorescence was noted in both RedEfish and Casper larvae.

Whole mount immunolocalization was performed to validate the presence of mScarlet and TTPA. GSG-T2A linker sites are not 100\% efficient peptide cleavage sites, which can cause either (1) mScarlet fused to exon 1 of Ttpa, which may potentially produce fluorescent but nonfunctional protein, or (2) skipped and decrease the production of Ttpa. This phenomenon has been described [43]. RedEfish embryos were fixed in $4 \%$ PFA and subjected to antibody staining with an anti-RFP antibody. Casper embryos were used as a negative control, while the c269 allelic variant embryo was used as a positive control; antiacetylated tubulin is used as a control antibody. All embryos are 3 dpf. Rfp was expressed in RedEfish brain, trunk, yolk syncytium and pectoral fins. Rfp was not detected in Casper embryos, but was detected in the brain of positive control c269 embryos (Supplementary Figure S2).

Immunolocalization with anti-TTPA validated that Ttpa is expressed in the zebrafish embryos (5 dpf) in olfactory pits, gill arches and digestive tract lining (Figure 3A). Western blot analysis was also used to evaluate the success of protein expression in RedEfish. As 
expected, Ttpa was detected at approximately 32 KDa in RedEfish, Casper and the c269 lines (24 hpf) (Figure 3B). If the mScarlet-Ttpa construct was produced but not hydrolyzed, we anticipated a protein band at $\sim 60 \mathrm{kDa}$ (sum of mScarlet $(26.4 \mathrm{kDa}$ ) and Ttpa (32.7 kDa)). No band for a larger protein at approximately $60 \mathrm{kDa}$ was observed. An antibody to Rfp was also used to determine if mScarlet protein is expressed in the RedEfish line, although this antibody has not previously been used with mScarlet. The anti-RFP antibody used for immunolocalization detected RFP in the RedEfish embryos, however, did not detect RFP in the c269 embryos.

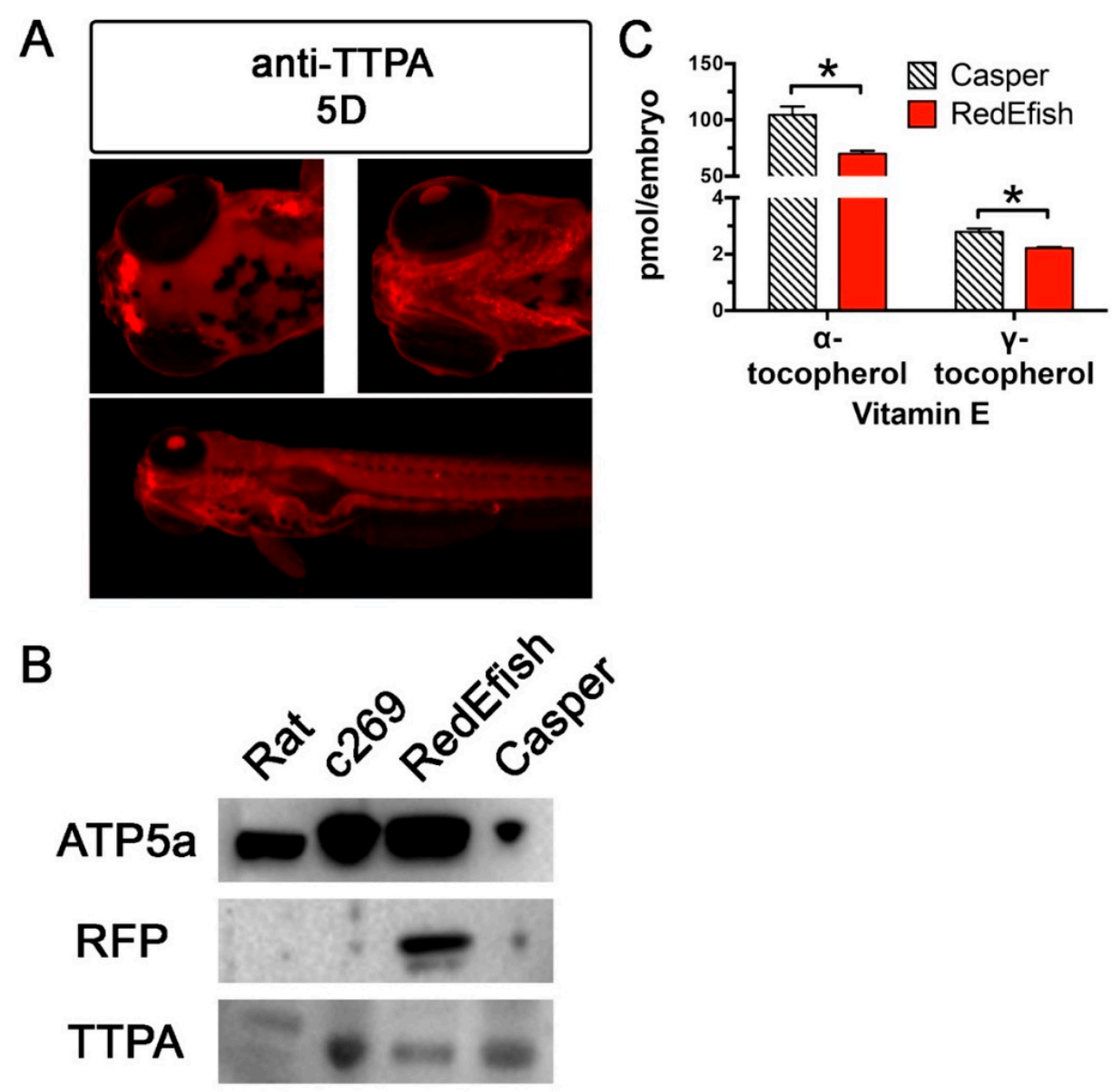

Figure 3. Immunolocalization and Western blot of Ttpa protein in rat liver and zebrafish embryos (c269, RedEfsh and Casper). (A) The 5D strain fish expressed Ttpa in olfactory pits, gill arches and gut lining at $5 \mathrm{dpf}$. Anti-Ttpa was used to detect and validate Ttpa protein expression in 5D embryos initially to determine regionalization followed by in vivo observation. Figure A panels were generated with the BZ-x700 microscope, processed with BZ-X Analyzer Software with image adjustments equally applied across all images in Adobe Photoshop. All images are taken at $2 \times$ magnification at the same exposure protocol. This figure was created with Adobe Photoshop, v21.2.1. (B) The same anti-Ttp antibody, used in a Western blot, confirmed that Ttpa expression is not affected by the insertion of the mScarlet coding sequence in RedEfish relative to Casper or the c269 transgenic lines. This antibody reacts poorly with rat liver protein. RFP was also detected in the RedEfish embryos, although not detected by blot in the rat liver, c269 or Casper zebrafish embryos. (C) Shown are $\alpha$ and $\gamma$-tocopherol concentrations (mean \pm standard deviation, pmol/embryo, ${ }^{*}=$ Student's $t$-test, $p=0.002$ and $p=0.001$, respectively) in 5 day old Casper (hatched bars) and RedEfish (red solid bars) embryos ( $n=5$ homogenate pools per group, $n=15$ embryos per pool). Both RedEfish and Casper embryos contained lower mean $\gamma$ - as compared with $\alpha$-tocopherol concentrations; the comparison of logarithmically transformed data for each fish line was significantly different $(p<0.0001$, Holm-Sidak's multiple comparisons test). 


\section{Embryo Morphology and Egg Quality Assessment}

Egg quality was assessed in F3 RedEfish and Casper embryos at 6 hpf (gastrulation), when ttpa is first expressed in zebrafish [28,29]. Egg volume was not significantly different between RedEfish $\left(0.220 \pm 0.024 \mathrm{~mm}^{3}\right)$ and Casper $\left(0.205 \pm 0.023 \mathrm{~mm}^{3}\right)$ embryos $(p=0.18$, $n=10$ per group). Morbidity and mortality outcomes at $5 \mathrm{dpf}$ were also similar with fewer than $5 \%$ of a given clutch experiencing a developmental deformity $(n=100$ embryos each in 3 independent spawning events). Finally, because of potential modification to Ttpa by insertion of the mScarlet coding sequence, VitE status was assessed in RedEfish and Casper embryos at $5 \mathrm{dpf}$. Both $\alpha$ - and $\gamma$-tocopherol concentrations were significantly lower in RedEfish relative to Casper strain embryos (Figure 3C). Importantly, the RedEfish had lower mean $\gamma$ - as compared with $\alpha$-tocopherol concentrations $(p<0.0001$, Holm-Sidak's multiple comparisons test), emphasizing that the Ttpa discriminatory capability in the RedEfish remained functional.

\section{Discussion}

We present the RedEfish, a new model for studying Ttpa localization and trafficking. This zebrafish embryo model will be useful to study vertebrate development and as the zebrafish grows to identify the specific tissue and cellular expression of Ttpa. Based on the concept that $\mathrm{mScarlet}$ accumulates in cells that synthesize Ttpa, we provide further support that Ttpa is associated with numerous developing embryonic structures, especially throughout the nervous system, circulatory system and digestive tract based on Ttpa presence established via expression of mScarlet. These data also suggest that VitE is required during development by these specific cells in these systems because in humans $[44,45]$ and mice [46-48] TTPA's known function is to traffic $\alpha$-tocopherol. Measurements of $\alpha$ and $\gamma$-tocopherol concentrations in the RedEfish documented that these fish discriminate between these tocopherols (Figure 3C), as expected for functional Ttpa [49].

Lecithotrophic animals, those that rely on maternal deposited yolk, are an important model for lipid and lipid-soluble vitamin metabolism during yolk utilization. The zebrafish embryo develops separately from its yolk [50,51], which is bound by the yolk syncytial layer (YSL) that secretes nutrients from the yolk into the developing organism. The YSL expresses many of the genes needed for lipid and lipid-soluble vitamin transport [52-54] likely facilitating the transfer of VitE from the yolk to the embryo. Zebrafish express the microsomal triglyceride transfer protein (Mttp) immediately after the gastrulation in the YSL, which facilitates apolipoprotein B (apoB) secretion to increase neutral lipid secretion and accumulation throughout the embryo until the yolk depletes $[55,56]$. Mice similarly require $m t t p$ to export triglyceride in apoB-containing lipoproteins and $m t t p$-null mice die midgestation $[57,58]$. Defects in $m t t p$ causing abetalipoproteinemia in humans also cause VitE deficiency [59]. Thus, VitE transport from the yolk likely depends on the lipid metabolic machinery of the YSL. The ttpa mRNA was found in zebrafish embryo YSL and early neural structures including the eye, brain and posterior tailbud [28,29]. We report mScarlet fluorescence is detected in the YSL in the zebrafish embryo throughout yolk depletion and is found as punctate expression throughout the larval digestive tract until at least $14 \mathrm{dpf}$. Ttpa may be involved in retrieving VitE from yolk stores and from the enterocytes upon first feeding at $5 \mathrm{dpf}$, although this suggestion has not been observed in other embryonic models. We previously reported that VitE-deficiency adversely impacts neural crest cells expressing sox10 [28], which are known precursors of the enteric nervous system. These data suggest that VitE may be important during enteric neuron maturation.

Ttpa, a cytosolic protein, localizes to recycling endosome, which is also marked by expression of Niemann-Pick $\mathrm{C} 1$ and $\mathrm{C} 2$ (Npc1 and 2). Both Npc1 and Npc2 are expressed specifically in the zebrafish embryo YSL [60], a metabolically active organ that exists up to $9 \mathrm{dpf}$ [61]. $\mathrm{Npc1}^{-/-}$zebrafish mutants have increased unesterified cholesterol in trunk neuromasts indicating localization of impaired recycling endosomal metabolism and possible colocalization of Ttpa [62], supported by early embryonic mScarlet expression in our line. Indeed, $\mathrm{NPC1}^{-/-}$mice experience negatively impacted hepatic and cortical 
VitE levels [63], with accumulation of VitE in lysosomal compartments [64]. Additionally, NPC1-like 1 mediates tocopherol uptake by human [65] and mouse [66] intestinal epithelial cells. Our model supports previous findings that Ttpa and Npc likely localize to the same cell or tissue types involving endosomal recycling and cholesterol trafficking, including neuromasts, the lateral line and the intestinal tract especially in $7 \mathrm{dpf}$ embryos.

The mScarlet fluorescence signal was not immediately apparent in the mosaic founder zebrafish nor in the early embryonic stages up to $5 \mathrm{dpf}$ in the heterozygote or homozygote RedEfish. Although some fluorescence was detected during this developmental window, successful transgenesis required molecular validation because of the yolk autofluorescence [67]. The bright yolk sac may be indicative of Ttpa and simultaneous mScarlet expression, however, that outcome is currently unclear. We hypothesized that the presence of VitE separate from yolk-derived transport may stimulate embryonic tissue expression of Ttpa and mScarlet. VitE supplementation increases Ttpa mRNA expression in isolated rat liver after food deprivation [68]. In addition, VitE supplementation stabilizes and prevents degradation of TTPA in HepG2 cells [69]. Punctate protein expression may also be achieved by VitE supplementation because TTPA colocalizes to lysosomes, as indicated in isolated mouse hepatocytes by LAMP1 and fluorescent tocopherol upon supplementation [70]. Feeding 5 dpf embryos induced red fluorescence detected at 7- and 14-dpf, the signal was, however, primarily localized to the gut and digestive tract lining rather than the liver, as expected. Larval zebrafish "guts" remain highly autofluorescent [71], possibly as a result of their microbiome [72]. Further investigation of the RedEfish model should exclude examination of the auto-fluorescent yolk and digestive tract, although these structures are still critical for dissecting the functions of VitE and Ttpa in embryonic development.

Importantly, VitE is associated with nervous system development. Chronically VitE deficient mice [73] and zebrafish [74] experience cognitive dysfunction resulting from brain specific lipid peroxidation. In addition, blocking translation of Ttpa prevented formation of the eye and brain of $24 \mathrm{hpf}$ zebrafish embryos [29]. Ttpa is found in the cerebellum of adult rats [75] and in mice with VitE deficiency caused by deletion of Ttpa exhibit lipofuscin accumulation as a result of oxidative damage specifically in the dorsal root ganglia (DRG) [76]. DRG from Ttpa ${ }^{-/-}$mice have increased apoptosis [77], causing reduced mechanosensitivity and excitability prevented only by very high levels of VitE supplementation [78]. Additionally, we found that the DRG was disrupted in VitE deficient zebrafish embryos [28]. Knowing this information, we anticipated mScarlet expression as a proxy for Ttpa expression in the DRG of adult zebrafish (Figure 1E). Thus, the mScarlet expression in the DRG of the RedEfish was expected. Nonetheless, we cannot rule out autofluorescence; however, it is unclear what would produce this punctate effect in $21 \mathrm{dpf}$ zebrafish embryos.

mScarlet can be visualized using a fluorescence microscope with an absorbance and emission spectra of $569 \mathrm{~nm}$ and $594 \mathrm{~nm}$, respectively. Guide RNA (gRNA) sequences were selected for a region $5^{\prime}$ of the first ttpa exon to create a polycistronic $2 \mathrm{~A}$ construct encoding $\mathrm{mScarlet}$ and ttpa in tandem. The T2A self-cleaving peptide has the highest cleavage efficiency of the 2A peptides and has been used to produce independent fluorophore and target proteins in immortalized cell lines, and zebrafish embryos [43]. We were able to confirm, using anti-TTPA that Ttpa is expressed in the RedEfish at $24 \mathrm{hpf}$, and in other transgenic fish lines (c269 and Casper, Figure 3B). We also confirm Rfp by Western blot analysis in the RedEfish (Figure 3B) and by whole mount immunolocalization with the anti-RFP; note that the c269 expresses RFP specifically in the brain [33] (Supplementary Figure S2). With regards to the construct used, the T2A site was chosen due to high "cleavage" efficiency for a 2A self-cleaving peptide sequence in zebrafish [43]. However, 2A sites present a technical challenge as some bi-cistronic proteins remain uncleaved because of ribosomal read-through or even falling-off [79]. Since VitE levels were found to be somewhat lower in RedEfish relative to the Casper line, it appears that some ribosomal skipping may be occurring to produce reduced Ttpa levels and thus reduced VitE levels in the embryo. Western blot analysis did not indicate reduced Ttpa expression nor did it 
show a larger unhydrolyzed protein consistent with an unhydrolyzed mScarlet and Ttpa. An additional potential mechanism for the observed lower embryonic VitE, is less VitE added to the developing egg by the adult female fish, as has been shown for chickens [80].

In summary, the RedEfish is a new model to study VitE trafficking in early embryonic development in a model organism suitable for further genetic modification and easy observation by external development. To confirm that the reporter construct was effectively integrated and coexpressed with ttpa, sequencing of the genomic region, Western blot analysis and immunolocalization was performed. Confirmation that the reporter construct does not impair Ttpa function was also performed by morphologic assessment of $6 \mathrm{hpf}$ embryos and VitE status of $5 \mathrm{dpf}$ embryos. Thus, we provide ample supporting evidence of the proper germ-line transmission of the mScarlet coding sequence $5^{\prime}$ of the first exon of ttpa. We report herein a fluorescent tagged Ttpa model to track VitE-dependent and Ttpa-dependent cells at the onset of development in the zebrafish embryo. This model will provide a powerful tool to evaluate the effect of VitE status, as we have previously shown $[24-28,81,82]$ with in vivo detection and fluorescent presentation of the VitE deficient phenotype.

Supplementary Materials: The following are available online at https:/ /www.mdpi.com/article/ 10.3390/antiox10060965/s1, Figure S1: Genotyping confirmation indicates successful genomic integration in heterozygote RedEfish, Figure S2: RFP expression confirmation in 3 days post-fertilization (dpf) c269, Casper and RedEfish.

Author Contributions: Conceptualization, B.H., J.L.D., E.H., R.L.T. and M.G.T.; Data curation, B.H. and C.B.; Formal analysis, B.H., J.L.D., J.Z. and C.W.; Funding acquisition, M.G.T.; Investigation, J.L.D., R.L.T. and M.G.T.; Methodology, B.H., C.B., J.Z. and R.L.T.; Project administration, C.B., R.L.T. and M.G.T.; Resources, J.L.D., C.W., E.H. and R.L.T.; Supervision, R.L.T. and M.G.T.; Writing—original draft, B.H.; Writing—review and editing, J.L.D., C.B., J.Z., C.W., E.H., R.L.T. and M.G.T. All authors have read and agreed to the published version of the manuscript.

Funding: The research reported in this publication was partially supported by the National Institute of Environmental Health Sciences of the National Institutes of Health under Award P30ES030287. The content is solely the responsibility of the authors and does not necessarily represent the official views of the National Institutes of Health.

Institutional Review Board Statement: All experimental protocols and methods were carried out in accordance with the animal use and care protocol (\#5068) approved by the Institutional Animal Care and Use Committee at Oregon State University.

Informed Consent Statement: Not applicable.

Data Availability Statement: Data is contained within the article and supplementary material.

Acknowledgments: The authors would like to thank the Center for Genomic Research and Biocomputing for their technical assistance. B.H. is supported by the Marion T. Tsefelas-Linus Pauling Institute Endowed Graduate Fellowship. M.G.T. is supported in part by the Ava Helen Pauling Endowment to the Linus Pauling Institute. J.Z. was supported in by the China Scholarship Council.

Conflicts of Interest: The authors declare no competing financial and/or non-financial interest in relation to the work described.

\section{References}

1. Evans, H.M.; Bishop, K.S. On the existence of a hitherto unrecognized dietary factor essential for reproduction. Science 1922, 56, 650-651. [CrossRef]

2. Shah, R.S.; Rajalakshmi, R.; Bhatt, R.V.; Hazra, M.N.; Patel, B.C.; Swamy, N.B.; Patel, T.V. Vitamin E status of the newborn in relation to gestational age, birth weight and maternal vitamin E status. Br. J. Nutr. 1987, 58, 191-198. [CrossRef]

3. Shamim, A.A.; Schulze, K.; Merrill, R.D.; Kabir, A.; Christian, P.; Shaikh, S.; Wu, L.; Ali, H.; Labrique, A.B.; Mehra, S.; et al. Firsttrimester plasma tocopherols are associated with risk of miscarriage in rural Bangladesh. Am. J. Clin. Nutr. 2015, 101, $294-301$. [CrossRef]

4. Gagne, A.; Wei, S.Q.; Fraser, W.D.; Julien, P. Absorption, transport, and bioavailability of vitamin e and its role in pregnant women. J. Obstet. Gynaecol. Can. 2009, 31, 210-217. [CrossRef] 
5. Baydas, G.; Karatas, F.; Gursu, M.F.; Bozkurt, H.A.; Ilhan, N.; Yasar, A.; Canatan, H. Antioxidant vitamin levels in term and preterm infants and their relation to maternal vitamin status. Arch. Med. Res. 2002, 33, 276-280. [CrossRef]

6. Scholl, T.O.; Chen, X.; Sims, M.; Stein, T.P. Vitamin E: Maternal concentrations are associated with fetal growth. Am. J. Clin. Nutr. 2006, 84, 1442-1448. [CrossRef]

7. Schuelke, M. Ataxia with Vitamin E Deficiency. GeneReviews ${ }^{\circledR}$ [Internet] 2005 May 20 [Updated 2016 Oct 13]. Available online: https:/ / www.ncbi.nlm.nih.gov/books/NBK1241/ (accessed on 30 March 2021).

8. Di Donato, I.; Bianchi, S.; Federico, A. Ataxia with vitamin E deficiency: Update of molecular diagnosis. Neurol. Sci. 2010, 31, 511-515. [CrossRef] [PubMed]

9. Chung, S.; Ghelfi, M.; Atkinson, J.; Parker, R.; Qian, J.; Carlin, C.; Manor, D. Vitamin E and phosphoinositides regulate the intracellular localization of the hepatic alpha-tocopherol transfer protein. J. Biol. Chem. 2016, 291, 17028-17039. [CrossRef]

10. Kono, N.; Arai, H. $\alpha$-Tocopherol transfer protein. In Vitamin E; Chemistry and Nutritional Benefits; Niki, E., Williamson, G., Marangoni, A.G., Gerrard, K.A., Eds.; Food Chemistry, Function and Analysis; Royal Society of Chemistry: Cambridge, UK, 2019; Volume 11, pp. 64-74.

11. Jauniaux, E.; Cindrova-Davies, T.; Johns, J.; Dunster, C.; Hempstock, J.; Kelly, F.J.; Burton, G.J. Distribution and transfer pathways of antioxidant molecules inside the first trimester human gestational sac. J. Clin. Endocrinol. Metab. 2004, 89, 1452-1458. [CrossRef] [PubMed]

12. Kaempf-Rotzoll, D.E.; Igarashi, K.; Aoki, J.; Jishage, K.; Suzuki, H.; Tamai, H.; Linderkamp, O.; Arai, H. Alpha-tocopherol transfer protein is specifically localized at the implantation site of pregnant mouse uterus. Biol. Reprod. 2002, 67, 599-604. [CrossRef]

13. Garcia, G.R.; Noyes, P.D.; Tanguay, R.L. Advancements in zebrafish applications for 21st century toxicology. Pharmacol. Ther. 2016, 161, 11-21. [CrossRef]

14. Driever, W.; Solnica-Krezel, L.; Schier, A.F.; Neuhauss, S.C.; Malicki, J.; Stemple, D.L.; Stainier, D.Y.; Zwartkruis, F.; Abdelilah, S.; Rangini, Z.; et al. A genetic screen for mutations affecting embryogenesis in zebrafish. Development 1996, 123, 37-46. [CrossRef]

15. Amsterdam, A.; Nissen, R.M.; Sun, Z.; Swindell, E.C.; Farrington, S.; Hopkins, N. Identification of 315 genes essential for early zebrafish development. Proc. Natl. Acad. Sci. USA 2004, 101, 12792-12797. [CrossRef]

16. Gonsar, N.; Coughlin, A.; Clay-Wright, J.A.; Borg, B.R.; Kindt, L.M.; Liang, J.O. Temporal and spatial requirements for Nodalinduced anterior mesendoderm and mesoderm in anterior neurulation. Genesis 2016, 54, 3-18. [CrossRef] [PubMed]

17. Kindt, L.M.; Coughlin, A.R.; Perosino, T.R.; Ersfeld, H.N.; Hampton, M.; Liang, J.O. Identification of transcripts potentially involved in neural tube closure using RNA sequencing. Genesis 2018, 56, e23096. [CrossRef]

18. Ma, P.; Swartz, M.R.; Kindt, L.M.; Kangas, A.M.; Liang, J.O. Temperature Sensitivity of Neural Tube Defects in Zoep Mutants. Zebrafish 2015, 12, 448-456. [CrossRef]

19. Lee, M.S.; Bonner, J.R.; Bernard, D.J.; Sanchez, E.L.; Sause, E.T.; Prentice, R.R.; Burgess, S.M.; Brody, L.C. Disruption of the folate pathway in zebrafish causes developmental defects. BMC Dev. Biol. 2012, 12, 12. [CrossRef] [PubMed]

20. Fishman, M.C. Zebrafish-The canonical vertebrate. Science 2001, 294, 1290-1291. [CrossRef] [PubMed]

21. Kirkwood, J.S.; Lebold, K.M.; Miranda, C.L.; Wright, C.L.; Miller, G.W.; Tanguay, R.L.; Barton, C.L.; Traber, M.G.; Stevens, J.F Vitamin C deficiency activates the purine nucleotide cycle in zebrafish. J. Biol. Chem. 2012, 287, 3833-3841. [CrossRef]

22. Lebold, K.M.; Lohr, C.V.; Barton, C.L.; Miller, G.W.; Labut, E.M.; Tanguay, R.L.; Traber, M.G. Chronic vitamin E deficiency promotes vitamin $\mathrm{C}$ deficiency in zebrafish leading to degenerative myopathy and impaired swimming behavior. Comp. Biochem. Physiol. C Toxicol. Pharmacol. 2013, 157, 382-389. [CrossRef]

23. Lebold, K.M.; Kirkwood, J.S.; Taylor, A.W.; Choi, J.; Barton, C.L.; Miller, G.W.; La Du, J.; Jump, D.B.; Stevens, J.F.; Tanguay, R.L.; et al. Novel liquid chromatography-mass spectrometry method shows that vitamin E deficiency depletes arachidonic and docosahexaenoic acids in zebrafish (Danio rerio) embryos. Redox Biol. 2013, 2, 105-113. [CrossRef] [PubMed]

24. McDougall, M.; Choi, J.; Kim, H.K.; Bobe, G.; Stevens, J.F.; Cadenas, E.; Tanguay, R.; Traber, M.G. Lethal dysregulation of energy metabolism during embryonic vitamin E deficiency. Free Radic. Biol. Med. 2017, 104, 324-332. [CrossRef]

25. McDougall, M.; Choi, J.; Kim, H.K.; Bobe, G.; Stevens, J.F.; Cadenas, E.; Tanguay, R.; Traber, M.G. Lipid quantitation and metabolomics data from vitamin E-deficient and -sufficient zebrafish embryos from 0 to 120 hours-post-fertilization. Data Brief 2017, 11, 432-441. [CrossRef] [PubMed]

26. Zhang, J.; Head, B.; Leonard, S.W.; Choi, J.; Tanguay, R.L.; Traber, M.G. Vitamin E deficiency dysregulates thiols, amino acids and related molecules during zebrafish embryogenesis. Redox Biol. 2021, 38, 101784. [CrossRef] [PubMed]

27. Head, B.; Ramsey, S.A.; Kioussi, C.; Tanguay, R.L.; Traber, M.G. Vitamin E Deficiency Disrupts Gene Expression Networks during Zebrafish Development. Nutrients 2021, 13, 468. [CrossRef] [PubMed]

28. Head, B.; La Du, J.; Tanguay, R.L.; Kioussi, C.; Traber, M.G. Vitamin E is necessary for zebrafish nervous system development. Sci. Rep. 2020, 10, 15028. [CrossRef] [PubMed]

29. Miller, G.W.; Ulatowski, L.; Labut, E.M.; Lebold, K.M.; Manor, D.; Atkinson, J.; Barton, C.L.; Tanguay, R.L.; Traber, M.G. The alpha-tocopherol transfer protein is essential for vertebrate embryogenesis. PLoS ONE 2012, 7, e47402. [CrossRef]

30. Bindels, D.S.; Haarbosch, L.; van Weeren, L.; Postma, M.; Wiese, K.E.; Mastop, M.; Aumonier, S.; Gotthard, G.; Royant, A.; Hink, M.A.; et al. mScarlet: A bright monomeric red fluorescent protein for cellular imaging. Nat. Methods 2017, 14, 53-56. [CrossRef] 
31. Velez, M.R. Generation of New Transgenic Zebrafish Lines for Studying Neuronal Circuits Underlying Behavior in Zebrafish. Master in Molecular Genetics and Biomedicine, Universidade Nova de Lisboa, RUN—Repositorio Universidade Nova. Available online: http:/ / hdl.handle.net/10362/58095 (accessed on 18 May 2021).

32. Antinucci, P.; Hindges, R. A crystal-clear zebrafish for in vivo imaging. Sci. Rep. 2016, 6, 29490. [CrossRef] [PubMed]

33. Goll, M.G.; Anderson, R.; Stainier, D.Y.; Spradling, A.C.; Halpern, M.E. Transcriptional silencing and reactivation in transgenic zebrafish. Genetics 2009, 182, 747-755. [CrossRef] [PubMed]

34. Kimmel, C.B.; Ballard, W.W.; Kimmel, S.R.; Ullmann, B.; Schilling, T.F. Stages of embryonic development of the zebrafish. Dev. Dyn. 1995, 203, 253-310. [CrossRef] [PubMed]

35. Aksoy, Y.A.; Nguyen, D.T.; Chow, S.; Chung, R.S.; Guillemin, G.J.; Cole, N.J.; Hesselson, D. Chemical reprogramming enhances homology-directed genome editing in zebrafish embryos. Commun. Biol. 2019, 2, 198. [CrossRef]

36. Truong, L.; Reif, D.M.; St Mary, L.; Geier, M.C.; Truong, H.D.; Tanguay, R.L. Multidimensional in vivo hazard assessment using zebrafish. Toxicol. Sci. 2014, 137, 212-233. [CrossRef] [PubMed]

37. Truett, G.E.; Heeger, P.; Mynatt, R.L.; Truett, A.A.; Walker, J.A.; Warman, M.L. Preparation of PCR-quality mouse genomic DNA with hot sodium hydroxide and tris (HotSHOT). Biotechniques 2000, 29, 52-54. [CrossRef] [PubMed]

38. Jardine, D.; Litvak, M.K. Direct yolk sac volume manipulation of zebrafish embryos and the relationship between offspring size and yolk sac volume. J. Fish Biol. 2003, 63, 388-397. [CrossRef]

39. Uusi-Heikkila, S.; Wolter, C.; Meinelt, T.; Arlinghaus, R. Size-dependent reproductive success of wild zebrafish Danio rerio in the laboratory. J. Fish Biol. 2010, 77, 552-569. [CrossRef]

40. Truong, L.; Harper, S.L.; Tanguay, R.L. Evaluation of embryotoxicity using the zebrafish model. Methods Mol. Biol. 2011, 691, 271-279. [CrossRef] [PubMed]

41. Podda, M.; Weber, C.; Traber, M.G.; Packer, L. Simultaneous determination of tissue tocopherols, tocotrienols, ubiquinols, and ubiquinones. J. Lipid Res. 1996, 37, 893-901. [CrossRef]

42. Axton, E.R.; Beaver, L.M.; St Mary, L.; Truong, L.; Logan, C.R.; Spagnoli, S.; Prater, M.C.; Keller, R.M.; Garcia-Jaramillo, M.; Ehrlicher, S.E.; et al. Treatment with nitrate, but not nitrite, lowers the oxygen cost of exercise and decreases glycolytic intermediates while increasing fatty acid metabolites in exercised zebrafish. J. Nutr. 2019, 149, 2120-2132. [CrossRef]

43. Kim, J.H.; Lee, S.R.; Li, L.H.; Park, H.J.; Park, J.H.; Lee, K.Y.; Kim, M.K.; Shin, B.A.; Choi, S.Y. High cleavage efficiency of a 2A peptide derived from porcine teschovirus-1 in human cell lines, zebrafish and mice. PLoS ONE 2011, 6, e18556. [CrossRef]

44. Kono, N.; Arai, H. Intracellular transport of fat-soluble vitamins A and E. Traffic 2015, 16, 19-34. [CrossRef]

45. Panagabko, C.; Morley, S.; Hernandez, M.; Cassolato, P.; Gordon, H.; Parsons, R.; Manor, D.; Atkinson, J. Ligand specificity in the CRAL-TRIO protein family. Biochemistry 2003, 42, 6467-6474. [CrossRef] [PubMed]

46. Arita, M.; Nomura, K.; Arai, H.; Inoue, K. Alpha-tocopherol transfer protein stimulates the secretion of alpha-tocopherol from a cultured liver cell line through a brefeldin A-insensitive pathway. Proc. Natl. Acad. Sci. USA 1997, 94, 12437-12441. [CrossRef] [PubMed]

47. Terasawa, Y.; Ladha, Z.; Leonard, S.W.; Morrow, J.D.; Newland, D.; Sanan, D.; Packer, L.; Traber, M.G.; Farese, R.V., Jr. Increased atherosclerosis in hyperlipidemic mice deficient in alpha -tocopherol transfer protein and vitamin E. Proc. Natl. Acad. Sci. USA 2000, 97, 13830-13834. [CrossRef]

48. Leonard, S.W.; Terasawa, Y.; Farese, R.V., Jr.; Traber, M.G. Incorporation of deuterated RRR- or all-rac-alpha-tocopherol in plasma and tissues of alpha-tocopherol transfer protein-null mice. Am. J. Clin. Nutr. 2002, 75, 555-560. [CrossRef]

49. Traber, M.G.; Siddens, L.K.; Leonard, S.W.; Schock, B.; Gohil, K.; Krueger, S.K.; Cross, C.E.; Williams, D.E. Alpha-tocopherol modulates Cyp3a expression, increases gamma-CEHC production, and limits tissue gamma-tocopherol accumulation in mice fed high gamma-tocopherol diets. Free Radic. Biol. Med. 2005, 38, 773-785. [CrossRef] [PubMed]

50. Kimmel, C.B.; Law, R.D. Cell lineage of zebrafish blastomeres. II. Formation of the yolk syncytial layer. Dev. Biol. 1985, 108, 86-93. [CrossRef]

51. Kimmel, C.B.; Law, R.D. Cell lineage of zebrafish blastomeres. I. Cleavage pattern and cytoplasmic bridges between cells. Dev. Biol. 1985, 108, 78-85. [CrossRef]

52. Miyares, R.L.; de Rezende, V.B.; Farber, S.A. Zebrafish yolk lipid processing: A tractable tool for the study of vertebrate lipid transport and metabolism. Dis. Model Mech. 2014, 7, 915-927. [CrossRef]

53. Quinlivan, V.H.; Farber, S.A. Lipid Uptake, Metabolism, and Transport in the Larval Zebrafish. Front. Endocrinol. (Lausanne) 2017, 8, 319. [CrossRef]

54. Wilson, M.H.; Rajan, S.; Danoff, A.; White, R.J.; Hensley, M.R.; Quinlivan, V.H.; Recacha, R.; Thierer, J.H.; Tan, F.J.; BuschNentwich, E.M.; et al. A point mutation decouples the lipid transfer activities of microsomal triglyceride transfer protein. PLoS Genet 2020, 16, e1008941. [CrossRef]

55. Schlegel, A.; Stainier, D.Y. Microsomal triglyceride transfer protein is required for yolk lipid utilization and absorption of dietary lipids in zebrafish larvae. Biochemistry 2006, 45, 15179-15187. [CrossRef]

56. Marza, E.; Barthe, C.; Andre, M.; Villeneuve, L.; Helou, C.; Babin, P.J. Developmental expression and nutritional regulation of a zebrafish gene homologous to mammalian microsomal triglyceride transfer protein large subunit. Dev. Dyn. 2005, 232, 506-518. [CrossRef]

57. Raabe, M.; Kim, E.; Veniant, M.; Nielsen, L.B.; Young, S.G. Using genetically engineered mice to understand apolipoprotein-B deficiency syndromes in humans. Proc. Assoc. Am. Physicians 1998, 110, 521-530. [PubMed] 
58. Raabe, M.; Flynn, L.M.; Zlot, C.H.; Wong, J.S.; Veniant, M.M.; Hamilton, R.L.; Young, S.G. Knockout of the abetalipoproteinemia gene in mice: Reduced lipoprotein secretion in heterozygotes and embryonic lethality in homozygotes. Proc. Natl. Acad. Sci. USA 1998, 95, 8686-8691. [CrossRef]

59. Rader, D.J.; Brewer, H.B., Jr. Abetalipoproteinemia. New insights into lipoprotein assembly and vitamin E metabolism from a rare genetic disease. JAMA 1993, 270, 865-869. [CrossRef]

60. Louwette, S.; Regal, L.; Wittevrongel, C.; Thys, C.; Vandeweeghde, G.; Decuyper, E.; Leemans, P.; De Vos, R.; Van Geet, C.; Jaeken, J.; et al. NPC1 defect results in abnormal platelet formation and function: Studies in Niemann-Pick disease type C1 patients and zebrafish. Hum. Mol. Genet 2013, 22, 61-73. [CrossRef] [PubMed]

61. Sakaguchi, T.; Kikuchi, Y.; Kuroiwa, A.; Takeda, H.; Stainier, D.Y. The yolk syncytial layer regulates myocardial migration by influencing extracellular matrix assembly in zebrafish. Development 2006, 133, 4063-4072. [CrossRef]

62. Tseng, W.C.; Loeb, H.E.; Pei, W.; Tsai-Morris, C.H.; Xu, L.; Cluzeau, C.V.; Wassif, C.A.; Feldman, B.; Burgess, S.M.; Pavan, W.J.; et al. Modeling Niemann-Pick disease type C1 in zebrafish: A robust platform for in vivo screening of candidate therapeutic compounds. Dis. Model Mech. 2018, 11. [CrossRef] [PubMed]

63. Ulatowski, L.; Parker, R.; Davidson, C.; Yanjanin, N.; Kelley, T.J.; Corey, D.; Atkinson, J.; Porter, F.; Arai, H.; Walkley, S.U.; et al. Altered vitamin E status in Niemann-Pick type C disease. J. Lipid Res. 2011, 52, 1400-1410. [CrossRef] [PubMed]

64. Yevenes, L.F.; Klein, A.; Castro, J.F.; Marin, T.; Leal, N.; Leighton, F.; Alvarez, A.R.; Zanlungo, S. Lysosomal vitamin E accumulation in Niemann-Pick type C disease. Biochim. Biophys. Acta 2012, 1822, 150-160. [CrossRef]

65. Narushima, K.; Takada, T.; Yamanashi, Y.; Suzuki, H. Niemann-pick C1-like 1 mediates alpha-tocopherol transport. Mol. Pharmacol. 2008, 74, 42-49. [CrossRef]

66. Reboul, E.; Soayfane, Z.; Goncalves, A.; Cantiello, M.; Bott, R.; Nauze, M.; Terce, F.; Collet, X.; Comera, C. Respective contributions of intestinal Niemann-Pick C1-like 1 and scavenger receptor class B type I to cholesterol and tocopherol uptake: In vivo v. in vitro studies. Br. J. Nutr. 2012, 107, 1296-1304. [CrossRef]

67. Shi, X.; Teo, L.S.; Pan, X.; Chong, S.W.; Kraut, R.; Korzh, V.; Wohland, T. Probing events with single molecule sensitivity in zebrafish and Drosophila embryos by fluorescence correlation spectroscopy. Dev. Dyn. 2009, 238, 3156-3167. [CrossRef] [PubMed]

68. Fechner, H.; Schlame, M.; Guthmann, F.; Stevens, P.A.; Rustow, B. alpha- and delta-tocopherol induce expression of hepatic alpha-tocopherol-transfer-protein mRNA. Biochem. J. 1998, 331 Pt 2, 577-581. [CrossRef]

69. Thakur, V.; Morley, S.; Manor, D. Hepatic alpha-tocopherol transfer protein: Ligand-induced protection from proteasomal degradation. Biochemistry 2010, 49, 9339-9344. [CrossRef]

70. Qian, J.; Morley, S.; Wilson, K.; Nava, P.; Atkinson, J.; Manor, D. Intracellular trafficking of vitamin E in hepatocytes: The role of tocopherol transfer protein. J. Lipid Res. 2005, 46, 2072-2082. [CrossRef] [PubMed]

71. Taormina, M.J.; Hay, E.A.; Parthasarathy, R. Passive and Active Microrheology of the Intestinal Fluid of the Larval Zebrafish. Biophys. J. 2017, 113, 957-965. [CrossRef] [PubMed]

72. Whipps, C.M.; Moss, L.G.; Sisk, D.M.; Murray, K.N.; Tobin, D.M.; Moss, J.B. Detection of autofluorescent Mycobacterium chelonae in living zebrafish. Zebrafish 2014, 11, 76-82. [CrossRef]

73. Fukui, K.; Nakamura, K.; Shirai, M.; Hirano, A.; Takatsu, H.; Urano, S. Long-term vitamin E-deficient mice exhibit cognitive dysfunction via elevation of brain oxidation. J. Nutr. Sci. Vitaminol. (Tokyo) 2015, 61, 362-368. [CrossRef]

74. McDougall, M.; Choi, J.; Truong, L.; Tanguay, R.; Traber, M.G. Vitamin E deficiency during embryogenesis in zebrafish causes lasting metabolic and cognitive impairments despite refeeding adequate diets. Free Radic. Biol. Med. 2017, 110, 250-260. [CrossRef]

75. Hosomi, A.; Goto, K.; Kondo, H.; Iwatsubo, T.; Yokota, T.; Ogawa, M.; Arita, M.; Aoki, J.; Arai, H.; Inoue, K. Localization of alpha-tocopherol transfer protein in rat brain. Neurosci. Lett. 1998, 256, 159-162. [CrossRef]

76. Yokota, T.; Igarashi, K.; Uchihara, T.; Jishage, K.; Tomita, H.; Inaba, A.; Li, Y.; Arita, M.; Suzuki, H.; Mizusawa, H.; et al. Delayed-onset ataxia in mice lacking alpha -tocopherol transfer protein: Model for neuronal degeneration caused by chronic oxidative stress. Proc. Natl. Acad. Sci. USA 2001, 98, 15185-15190. [CrossRef] [PubMed]

77. Finno, C.J.; Bordbari, M.H.; Gianino, G.; Ming-Whitfield, B.; Burns, E.; Merkel, J.; Britton, M.; Durbin-Johnson, B.; Sloma, E.A.; McMackin, M.; et al. An innate immune response and altered nuclear receptor activation defines the spinal cord transcriptome during alpha-tocopherol deficiency in Ttpa-null mice. Free Radic. Biol. Med. 2018, 120, 289-302. [CrossRef] [PubMed]

78. Finno, C.J.; Peterson, J.; Kang, M.; Park, S.; Bordbari, M.H.; Durbin-Johnson, B.; Settles, M.; Perez-Flores, M.C.; Lee, J.H.; Yamoah, E.N. Single-cell RNA-seq reveals profound alterations in mechanosensitive dorsal root ganglion neurons with vitamin e deficiency. iScience 2019, 21, 720-735. [CrossRef] [PubMed]

79. Liu, Z.; Chen, O.; Wall, J.B.J.; Zheng, M.; Zhou, Y.; Wang, L.; Vaseghi, H.R.; Qian, L.; Liu, J. Systematic comparison of 2A peptides for cloning multi-genes in a polycistronic vector. Sci. Rep. 2017, 7, 2193. [CrossRef]

80. Cherian, G.; Sim, J.S. Egg yolk polyunsaturated fatty acids and vitamin E content alters the tocopherol status of hatched chicks. Poult. Sci. 1997, 76, 1753-1759. [CrossRef] [PubMed]

81. McDougall, M.; Choi, J.; Magnusson, K.; Truong, L.; Tanguay, R.; Traber, M.G. Chronic vitamin E deficiency impairs cognitive function in adult zebrafish via dysregulation of brain lipids and energy metabolism. Free Radic. Biol. Med. 2017, 112, 308-317. [CrossRef]

82. Miller, G.W.; Labut, E.M.; Lebold, K.M.; Floeter, A.; Tanguay, R.L.; Traber, M.G. Zebrafish (Danio rerio) fed vitamin E-deficient diets produce embryos with increased morphologic abnormalities and mortality. J. Nutr. Biochem. 2012, 23, 478-486. [CrossRef] 